\title{
$\mathrm{J}$

\section{WHAT IS A HERPETOLOGIST AND HOW CAN I BECOME ONE?}

\author{
J. WHITFIELD GIBBONS ${ }^{1}$ AND MICHAEL E. DORCAS²
}

\author{
${ }^{1}$ University of Georgia, Savannah River Ecology Lab, Drawer E, Aiken, South Carolina 29802 \\ ${ }^{2}$ Department of Biology, Davidson College, Davidson, North Carolina 28035-7118
}

\begin{abstract}
The following is the first in the JNAH series in which we address a variety of topics on herpetology based on essays from our upcoming book "How to Be a Herpetologist,". We will also answer frequently asked questions we and other professional herpetologists receive from students, colleagues, and the general public about herpetology as a career or an avocation.
\end{abstract}

Few valid reasons can be given for why any professional herpetologist has not answered the question "How can I become a herpetologist?" at least once and maybe dozens of times. Perhaps he escapes to the field or his laboratory virtually all the time, eschewing people the way a leopard frog does a gartersnake, making sure no one has opportunity to ask. Or maybe she does not make herpetology look like a very fun profession, so that the question is more likely to be, "How can I avoid doing what you do?" Or more likely the herpetologist has heard such an inquiry many times but because no succinct answer was apparent, the letter, email, or in-person question was not answered. If you are a herpetologist and any of these are your reasons for not inspiring the question from youngsters, or even oldsters, about how they could become a herpetologist, and then giving them an answer, shame on you. If you are not a herpetologist and would like to know about how to become one, read on.

The first step in addressing the question is to make sure the questioner and the answerer have the same definition of what herpetology is. The literal definition is that herpetology is the study of reptiles and amphibians, but many people asking the question really simply mean, "How can I be involved with reptiles and amphibians," rather than necessarily wanting to know how to plan for a research career in herpetology. Taking the issue one step further, some herpetologists even argue about what a reptile is as both turtles and crocodilians, based on modern evolutionary biology, have been excluded from the class by some authorities and retained by others. Arguments have even been made by some professional herpetologists that phylogenetically all snakes are really lizards and that some lizards are more closely related to what most people call snakes than they are to other lizards.
Taxonomic issues of this nature, which are often represented by strong opinions of particular individuals, can be very confusing to the novice and are unlikely to make someone enthusiastic about becoming a herpetologist. So let's face it. The classic groups most people think of as falling under the term herpetology are the old-fashioned reptiles (snakes, lizards, amphisbaenians, turtles, tuatara, and crocodilians) and amphibians (frogs, salamanders, and caecilians). We will stick to that terminology for now in considering how to respond to someone who wants to be a herpetologist.

When people ask the question, "How can I become a herpetologist?" some may have in mind working with reptiles and amphibians at a nature center or zoo, being a state or federal wildlife manager, or simply having herpetology as a hobby. Many, however, are thinking in terms of pursuing a professional career which almost invariably requires a college degree of some sort. The steps of getting a college degree for people who like herpetology usually involve majoring in college in biology, zoology, ecology, or some other broad field of science and then specializing in the study of reptiles or amphibians. College requirements in the field of herpetology are a strong background in ecology and zoology with an array of additional courses in genetics, mathematics, wildlife ecology, animal behavior, conservation biology, and other special areas that are of interest. Most herpetologists get degrees in the life sciences (e.g., Biology, Zoology, Ecology) but specialize in reptiles and amphibians in some way.

Whatever field you go into, making good grades in high school and college is always important. In looking at the academic background of a variety of individuals who would be considered to be the best herpetologists today, some have obtained their undergraduate degrees from state universities and some from elite 
private universities and colleges. People attend a particular college for a variety of reasons, with financial considerations often being a deciding factor. At this academic stage any standard accredited college that meets your financial needs for undergraduate study should provide you opportunity to excel academically, an important consideration for graduate studies. However, some small colleges and larger universities are noted for having undergraduate programs that offer students experiences in herpetological research and training, usually because of the presence of particular faculty members interested in reptiles and amphibians. A specific choice of universities is especially important for graduate school where you will want to focus on a particular topic and be certain that a professor is available to serve as a mentor in your area of interest. However, if you can become involved in an undergraduate program that offers students opportunities to become involved in herpetological research at an early stage, this can be an invaluable asset for one's career. Thorough internet searches and talking to established herpetologists about recommendations for colleges and professors with whom to work are strongly advised for both graduate and undergraduate degrees.

In our experience, one of the most important steps that anyone interested in being a herpetologist can take is to make contacts with individuals who can serve as mentors. Most successful herpetologists today have had people who encouraged them at various stages and provided advice and guidance. The old adage of "it's not what you know, it's who you know" holds for herpetology as well as it does for politics, sports, or business. Mentors cannot guarantee success, but they can often provide opportunities that someone with the proper drive and talents can turn into successful ventures. Luck is always a haphazard part of the formula for all of life's pathways, but having a good counselor at an early stage can shift the odds in your favor.

Finding a mentor who is a professional herpetologist may be a difficult task on a local scale under certain circumstances. So meanwhile try developing personal contacts with other people who have similar interests in reptiles and amphibians and who are at approximately the same stage as you. This can be a positive step. Before becoming involved with true mentors both of us found neighborhood friends who wanted to go into the field to collect reptiles and amphibians. Even a trip to a zoo or nature park that has reptiles and amphibians can be enhanced if someone equally interested accompanies you. Joining one of the amateur herp clubs that are now in many parts of the country is always a good way to acquire new friends interested in herpetology and often can lead the way to finding a more experienced adviser.

In addition to acquiring mentors and like-minded colleagues, we advise anyone thinking about a professional career in herpetology, especially in an academic or museum setting, to read as many books and scientific papers on reptiles and amphibians as possible and excel while getting a broad-based college education. Spend endless hours outdoors observing reptiles and amphibians and their interactions with other animals and plants. Learn about their feeding, breeding, and other habits through observations of captive specimens. Try to volunteer at local zoos, museums, and colleges that conduct research on amphibians and reptiles. Once you have gone as far academically as you care to, find out who will hire you for a job working with or around reptiles and amphibians based on your level of training and area of expertise. If you can't find a paying job as a herpetologist, make a living some other way and volunteer in your spare time. Many people who have other careers become excellent herpetologists by reading, getting together with other people interested in herpetology (such as a local, regional, or state herp societies), and having experiences with herps in the field or as pets.

In addition to the generic question answered above of how someone goes about becoming a professional herpetologist, a series of more specific questions can be asked, and have been, by people ranging in age from early grade school to later-life adults. No single answer will fit everyone as circumstances vary considerably. But all have in common that the person asking the question was intrigued with reptiles, amphibians, or both and wanted to be involved with them in some way. The following FAQs are examples derived from some of the essay topics in the book "How To Be A Herpetologist." Each of these and other topics related to "What Is a Herpetologist and How Can I Become One?" will be addressed in future issues of JNAH:

Q. What courses in high school are important for someone who wants to become a professional herpetologist at an academic institution?

Q. What are the opportunities for personal advancement if you are a herpetologist in an academic or museum job?

Q. What are your most and least favorite times as a herpetologist?

Q. How much money do herpetologists make?

Q. What training do I need to become a herpetologist and what types of organizations would be most likely to hire me?

Q. What are the best websites to find out about herpetology (jobs, identification of species, university programs, etc.)?

\section{ACKNOWLEDGMENTS}

We thank numerous colleagues, including former students, for discussing herpetological topics with us over the years and contributing to answering various versions of the questions asked by so many students and other herpetological enthusiasts. In particular we thank the many people, young and old, whose questions have prompted us and other professional herpetologists to give thought to the issue over the years and try to provide answers that are both encouraging yet realistic. We also appreciate the efforts of the 1985 SSAR committee (Henri C. Seibert [Chairman], Ralph W. Axtell [SSAR Pres., 1983], Neil B. Ford, and Martin J. Rosenberg) for addressing many of the questions being asked about how to make herpetology a career. 